\title{
Exhaled Breath Analysis in Diagnosis of Malignant Pleural Mesothelioma: Systematic Review
}

\author{
Zehra Nur Töreyin ${ }^{1, *} \mathbb{D}$, Manosij Ghosh ${ }^{1} \mathbb{C}$, Özlem Göksel ${ }^{2}$, Tuncay Göksel ${ }^{3}$ and \\ Lode Godderis 1,4 (D) \\ 1 University of Leuven (KU Leuven), Department of Public Health and Primary Care, Centre for Environment \\ and Health, 3000 Leuven, Belgium; manosij.ghosh@kuleuven.be (M.G.); lode.godderis@kuleuven.be (L.G.) \\ 2 Ege University, Faculty of Medicine, Department of Pulmonary Medicine, Division of Immunology, \\ Allergy and Asthma, Laboratory of Occupational and Environmental Respiratory Diseases, Bornova, \\ 35100 Izmir, Turkey; goksel.ozlem@gmail.com \\ 3 Ege University, Faculty of Medicine, Department of Pulmonary Medicine, Bornova, 35100 Izmir, Turkey; \\ tuncaygoksel@gmail.com \\ 4 Idewe, External Service for Prevention and Protection at Work, 3001 Heverlee, Belgium \\ * Correspondence: ntreyin@gmail.com
}

Received: 18 December 2019; Accepted: 2 February 2020; Published: 10 February 2020

\begin{abstract}
Malignant pleural mesothelioma (MPM) is mainly related to previous asbestos exposure. There is still dearth of information on non-invasive biomarkers to detect MPM at early stages. Human studies on exhaled breath biomarkers of cancer and asbestos-related diseases show encouraging results. The aim of this systematic review was to provide an overview on the current knowledge about exhaled breath analysis in MPM diagnosis. A systematic review was conducted on MEDLINE (PubMed), EMBASE and Web of Science databases to identify relevant studies. Quality assessment was done by the Newcastle-Ottawa Scale. Six studies were identified, all of which showed fair quality and explored volatile organic compounds (VOC) based breath profile using Gas Chromatography Coupled to Mass Spectrometry (GC-MS), Ion Mobility Spectrometry Coupled to Multi-capillary Columns (IMS-MCC) or pattern-recognition technologies. Sample sizes varied between 39 and 330. Some compounds (i.e, cyclohexane, P3, P5, P50, P71, diethyl ether, limonene, nonanal, VOC IK 1287) that can be indicative of MPM development in asbestos exposed population were identified with high diagnostic accuracy rates. E-nose studies reported breathprints being able to distinguish MPM from asbestos exposed individuals with high sensitivity and a negative predictive value. Small sample sizes and methodological diversities among studies limit the translation of results into clinical practice. More prospective studies with standardized methodologies should be conducted on larger populations.
\end{abstract}

Keywords: malignant pleural mesothelioma; exhaled breath analysis; volatile organic compounds; exhaled breath condensate

\section{Introduction}

Malignant pleural mesothelioma (MPM) is a rare but aggressive tumor arising from mesothelial cells of pleural membranes [1]. Globally, 30,443 new MPM cases were estimated from the GLOBOCAN database in 2018 [2]. Mortality trajectories show an increase in annual rates of MPM deaths globally, contrary to popular belief [3,4]. It has been more than 50 years since Wagner et al., established the relationship between asbestos fibers and histologically proven MPM in the miners and their households who employed in asbestos rich areas of South Africa [5]. Doll et al., have linked the lung cancer diagnosis of a group of workers with their past asbestos exposure [6]. It has been well established that exposure to mineral fibers such as asbestos and erionite is the main cause of MPM [7]. Asbestos is the 
commercial umbrella term for six types of naturally occurring silicate fibers, all of which have been considered as carcinogenic to humans by International Agency for Research on Cancer (IARC) [8]. Erionite is another naturally occurring mineral fiber belonging to the zeolite minerals. Its chain-like structure resembles that of amphibole asbestos and was found to have more potent carcinogenic effects on human mesothelial cells $[9,10]$. Indeed, all types of mineral fibers showing asbestiform disposition have potential to cause lung cancer and MPM, depending on their aspect ratio (length to width) and bio-persistence [11,12].

Asbestos fibers migrate towards pleura following inhalational exposure and may incite carcinogenesis independent of a safe exposure limit. Several hypotheses have been proposed to explain asbestos-induced diseases. The most accepted ones include the formation of highly reactive hydroxyl radical through the Haber-Weiss reaction which is produced by the interaction of superoxide $\left(\mathrm{O}_{2}{ }^{-}\right)$ and hydrogen peroxide $\left(\mathrm{H}_{2} \mathrm{O}_{2}\right)$ and catalyzed by asbestos surface iron. In addition, reactive oxygen radicals (ROS), generated mainly by macrophages, but also by lung fibroblasts and mesothelial cells, contribute to asbestos-induced inflammation $[13,14]$. Persistent accumulation of ROS may cause abnormal DNA repair and DNA damage, leading to carcinogenesis (Figure 1). Moreover, Tumor Necrosis Factor TNF- $\alpha$ may activate nuclear transcription factor (NF- $\kappa B$ ) which increases the durability of mesothelioma cells and hence, eases their duplication. Asbestos also promotes the phosphorylation of mitogen-activated protein kinase and extracellular signal-regulated kinases 1 and 2 , generating the over expression of proto oncogenes. In addition, research on mesothelioma genome supports the role of inactivated tumor suppressor genes encoded by cyclin-dependent kinase inhibitor 2A (CDKN2A), BRCA1 associated protein 1 (BAP1) and neurofibromin 2 (NF2) [15-17].

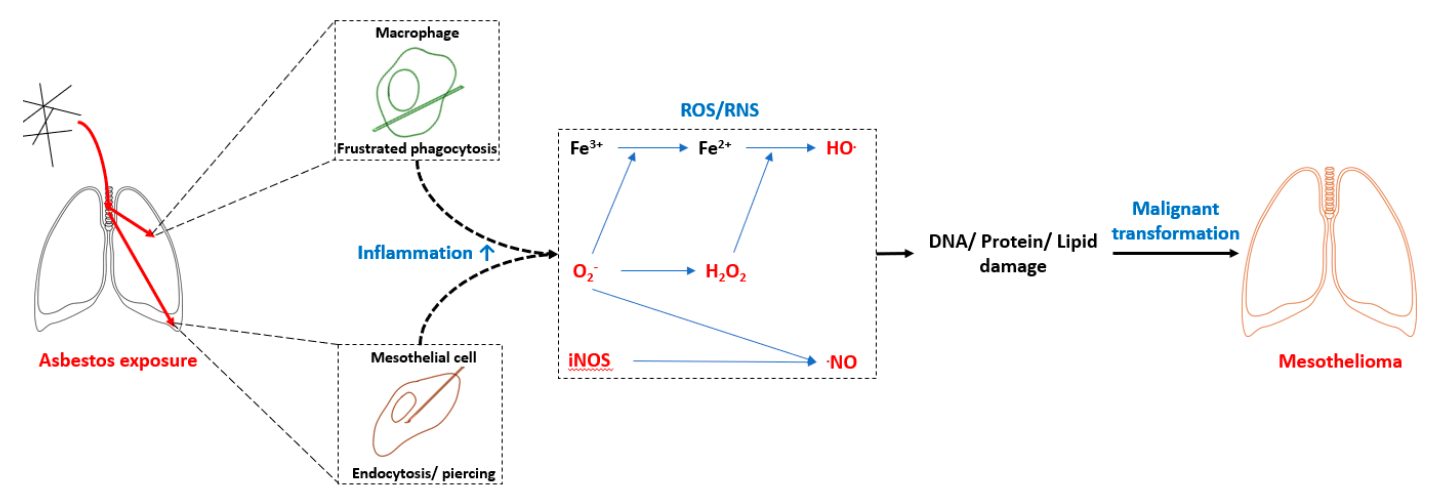

Figure 1. Asbestos induced inflammatory process. ROS—reactive oxygen species; RNS-reactive nitrogen species; iNOS—inducible nitric oxide synthase.

Patients with asbestos exposure history along with compatible computerized tomography (CT) findings for mesothelioma usually undergo thoracoscopy for histological investigation and tumor staging. However, due to morphological heterogeneity of tumor cells, even sufficient tissue may remain inadequate for the exact diagnosis. In addition, metastasis from other sites or reactive effusions may complicate diagnosis [18]. Therefore, it is difficult to detect MPM at the very early stages. In addition to the histological challenges, thoracoscopy can be contraindicated in a group of patients. For instance, owing to the insidious course of MPM, patients are generally admitted in advanced or at terminal stages, with poor performance scores ruling out an invasive procedure. In addition, MPM is prominent in the elderly who likely have multiple comorbidities.

Immune cytochemical markers in tissue or effusion are recommended to distinguish benign versus malignant mesothelial proliferations and mesothelioma versus other malignancies. At least two positive markers for mesothelioma (i.e., calretinin, cytokeratin 5/6, Wilms Tumor (WT1) and podoplanin (D240) and at least two negative markers for adenocarcinoma (thyroid transcription factor-1, carcinoembryonic antigen and Ber-EP4 antibody) are recommended as complimentary to other diagnostic procedures [18]. 
Due to the challenges with diagnosis and unfavorable effect of late diagnosis on disease outcome, as well as the predicted burden of MPM in the future, there is excessive research interest in the discovery of potential biomarkers of MPM. Among them, studies on tissue and blood biomarkers (i.e., mesothelin, osteopontin, fibulin-3, high mobility group box-1 (HMGB1) protein, aquaporin 1, microRNAs, proteomics-based biomarkers) have shown promising results [19-26]. Soluble mesothelin related peptide (SMRP) is the most studied biomarker and has been approved by the Food and Drug Administration (FDA) to be used in MPM diagnosis. It is expressed as membrane-bound peptides from healthy mesothelial cells and becomes detectable in the bloodstream after cleavage of the membrane-bound mesothelin. Although the role of mesothelin within mesothelioma carcinogenesis is ambiguous, several hypotheses emphasize its role within invasion via interaction with mucin MUC16 and the NF-KB signalling pathway [13]. Some studies on the diagnostic value of SMRP in asbestos exposed population reported a $68.2-75 \%$ sensitivity and $80.5-96.2 \%$ specificity in distinguishing MPM with benign pleural diseases [19-21]. Renal failure was found to affect its serum level [19]. Moreover, particular polymorphisms within the MSLN gene were found to be related with high levels in healthy subjects [22,23]. Hence, clinical findings should be addressed carefully when interpreting high serum levels. The duration of asbestos exposure was weakly or not correlated with SMRP levels in several studies $[20,24]$. In a meta-analysis, the overall sensitivity and specificity of osteopontin in MPM diagnosis were found 0.65 (95\% CI: 0.60-0.70) and 0.81 (95\% CI: 0.78-0.85), respectively [27]. Some recent studies have shown that the combined use of these potential biomarkers in asbestos exposed population may improve the accuracy of the diagnostic performance of individual markers [28-31].

Despite these efforts, there is still dearth of information on non-invasive biomarkers to detect early metabolic and inflammatory changes of MPM in asbestos-exposed individuals. In the context of MPM management, a good biomarker should be sensitive and specific enough to discriminate an MPM patient from a healthy person. Moreover, it should be predictive enough to catch the early precursors of malignant transformation in an asbestos-exposed population. The latter would avoid a group of asbestos exposed workers unnecessarily undergoing invasive diagnostic procedures.

The aim of this review is to provide an overview on the current knowledge about the use of exhaled breath analysis in MPM diagnosis as well as to give insights into potential histopathologic backgrounds of the breath profile changes detected. Hence, in the following sections, we will summarize the methodological aspects of exhaled breath analysis and the findings of available studies.

\section{Exhaled Breath Analysis}

\subsection{Exhaled Breath Composition}

Exhaled breath is the biological matrix for thousands of markers of exogenous or endogenous origin. In its physical structure, it is composed of three compartments: volatile fraction, gaseous fraction (i.e., fractional exhaled breath-FeNO) and exhaled breath condensate (EBC) [32]. Each of these components carries different biochemical products reflecting lung and peripheral body metabolism. For instance, EBC reflects airway lining biofluid composition while volatile fraction carries numerous organic compounds which have high vapor pressures and become volatile in ambient temperatures [33]. Different sampling and pre-treatment methods are implemented when studying these fractions (Figure 2).

Volatile organic compounds (VOCs) constitute the volatile fraction found in exhaled breath in very small amounts ranging from parts per trillion volume (pptv) to parts per billion volume (ppbv) [32,34]. They can be generated through metabolic processes of biologic systems, environmental sources (i.e., fuel combustion, cigarette smoke, fragrances, ingestion of drinks or food, drugs) or the metabolism of airway and gut microbiome. VOCs generated through metabolic pathways may arise from the respiratory system or from other systemic sources [35]. Compounds of the systemic origins dissolve into the blood and transport from alveolar circulation into alveolar space by a passive diffusion mechanism. The relative concentrations in alveolar space in blood and in adipose tissue are determined 
by their "fat-to-blood" and "blood-to-air" partition coefficients. The latter also indicates whether organic compounds in blood can be excreted via breath or not [34,36]. In addition, cardiac output and alveolar minute volume of subjects also influence VOC concentrations in exhaled breath. Exposure to several environmental contaminants can also be detected based on identification of the substance or metabolites in the breath (i.e., measurement of exhaled methyl-tertiary butyl ether (MTBE) and its metabolite tertiary butyl alcohol (TBA) in the exhaled breath of gasoline workers) [37].

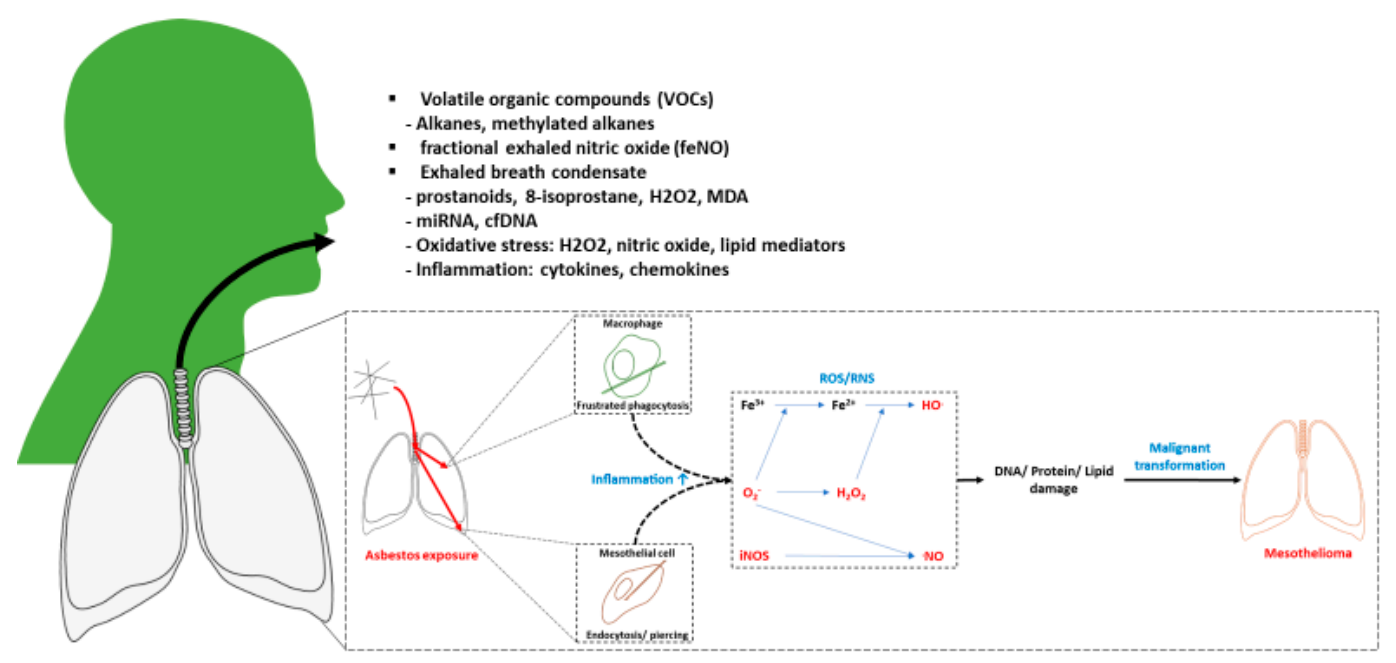

Figure 2. Exhaled breath composition. MDA—malondialdehyde.

The identification of VOCs related with tumor metabolism show a promising future in the screening and diagnosis of several cancers [34]. Possible mechanisms of cancer-related VOC emissions include (1) persistent oxidative stress-induced lipid peroxidation of polyunsaturated fatty acids (PUFAs) (i.e., emission of alkanes, alkenes and aldehydes following cell- and mitochondrial-membrane perturbations by ROS attacks) (2) induction of cytochrome p-450 enzymes by environmental carcinogens and ROS molecules (3) overexpression of cytochrome p-450 enzymes in several tumor types, such as breast tumors, (4) cancer cell metabolism shift from oxidative phosphorylation to aerobic glycolysis, (5) molecular alterations in oncogenes and tumor suppressor genes [34,38-41].

VOCs have been extensively studied in lung cancer in vivo and in vitro. Of these identified compounds, many studies reported lipid peroxidation (i.e., decane, heptanal, octane, undecane) and mevalonate (i.e., isoprene) pathways, related ones being high in lung cancer compared to healthy controls [41-43]. Moreover, it has been suggested that [41] peroxidation processes may produce cancer-specific VOCs given the hypothesis that lung cancer cells present altered phospholipid profiles compared to that of healthy cells [44]. However, none of these markers have been translated into clinical practice yet.

Fractional exhaled nitric oxide (FeNO) reflects the inflammatory condition of airways. A few studies have shown elevated FeNO levels in asbestos-exposed individuals [45-47].

EBC is another breath-derived matrix collected by cooling exhaled air at temperatures of $4{ }^{\circ} \mathrm{C}$ or lower, during spontaneous breathing [33,48]. Its main constituent is water, which makes EBC a highly diluted biofluid, while the remaining part is constituted by respiratory droplets carrying oxidative stress-related biomarkers $\left(\mathrm{H}_{2} \mathrm{O}_{2}, 8\right.$-isoprostane), proinflammatory and inflammatory mediators (NOx, prostanoids, leukotriens), DNA and miRNA. EBC composition was proposed to be reflective of the airway lining fluid making up the essential part of the pulmonary host defense system [33,48,49]. EBC analysis is also promising in occupational settings as it provides non-invasive and repeatable access to biomarkers of exposure and effect [50]. Its constituents and volume are supposed to be affected by circadian rhythm, age, sex, diet and drugs as well as pulmonary and extra-pulmonary diseases; hence, studies with human samples should account for these potential confounders [33]. 
Oxidative stress and inflammatory biomarkers, particularly 8-isoprostane and $\mathrm{H}_{2} \mathrm{O}_{2}$, were reported to be consistently high in the EBC of former asbestos-exposed individuals in several studies $[15,45,47]$. Of these, 8-isoprostane is generated following perturbation of membrane arachidonic acids by free radicals and is hence presumed to be more specific to lipid peroxidation compared to other oxidative stress biomarkers [48,51]. In addition, higher LTB4 levels were found in the EBC of asbestos-exposed individuals. One study reported a correlation between EBC LTB4 levels and the severity of radiological findings and lung function impairment in asbestosis patients [52].

Human studies on the exhaled breath biomarkers of cancer and asbestos-related diseases have shown encouraging results. However, limitations caused by unstandardized methodologies and small population sizes of the studies are likely to hamper their translation into clinical practice.

\subsection{Sample Collection}

A breath sample can be collected by polymeric bags, canisters or sorbent tubes to analyze volatile fraction [53]. Polymeric bags are made up of inert materials in order to avoid reactions with the breath sample and have the advantage of a low cost and ease of use. However, contamination with phenol, $\mathrm{N}, \mathrm{N}$-dimethylacetamide, carbon disulfide, and carbonyl sulfide was reported with some types [53,54]. The use of disposable bags would reduce contamination with cleaning agents. Moreover, the use of inert gases (i.e., ultra-pure nitrogen) for cleaning has been shown to be effective for repeated uses of polymeric bags [55]. Canisters are durable and avoid degradation of breath. However, they are expensive and need specific agents for cleaning, that might emit VOCs [53,55].

Breath can be sampled directly onto an analytical hardware or collected and concentrated through pre-treatment procedures before analysis $[53,56]$. Pre-concentration methods include VOC adsorption onto sorbent-containing thermal desorption (TD) traps or via solid-phase microextraction fibers (SPME) [53].

There are several issues to be considered during VOC sampling. The first is correction for exogenous volatiles, which can be in part achieved by subtracting ambient VOC concentrations from exhaled VOC concentrations or by breathing inhalation/exhalation filters before sampling. Decision on breath sample type is another issue to be considered as alveolar breath is more reflective of endogenous VOCs compared to that of total breath. Alveolar fraction can be obtained by disposing of the first $150 \mathrm{ml}$ of forced-expiratory air samples corresponding to dead space [57] or ideally, by continuous monitoring of $\mathrm{CO}_{2}$, which is reflective of alveolar-gas exchange. The latter is based on targeted breath sampling in parallel with the end-tidal $\mathrm{CO}_{2}$ levels [32,58]. Moreover, some commercial breath sampling devices are able to capture the end-tidal air [32]. Sampling duration and breathing pattern should also be considered during sampling as they may affect the breath profile [53].

During the sampling process of EBC, subjects breathe tidally over a predetermined period of time into a condensate/cooler device coated with either teflon, polypropylene, glass, silicone or aluminium [55,57]. It is recommended to refrain from exercise at least one hour in advance in order to decrease breath flow rates. In addition, periodic swallowing is recommended to avoid saliva contamination. Breath can also be affected by volatile constituents within ambient air; hence, a filter applied onto inhalation valve can help to reduce the environmental contamination of EBC. It is suggested to analyze the condensate as immediately as possible. Otherwise, freeze-drying and storage of the samples at $-80^{\circ} \mathrm{C}$ applied right after sampling are recommended procedures [55]. If the samples have been at $-80^{\circ} \mathrm{C}$ until analysis, transferring the samples into capped glass tubes within a controlled environment (i.e., via a laminar flow cabinet) before storage is recommended in order to decrease possible sample contamination by environmental air) [59].

\subsection{Detection Methods}

Exhaled breath detection can be addressed via two distinct methods. The first involves analytical techniques based on the identification of individual compounds. The second is pattern recognition 
of VOCs by utilizing sensor technology which—contrarily to analytical chemical methods—does not identify specific compounds [36,55].

\subsubsection{Analytical Methods}

Gas Chromatography Coupled to Mass Spectrometry (GC-MS) is still accepted as the golden standard method for VOC analysis and detects an extensive range of VOC profiles with high sensitivity and specificity. The operating principle is based on separation of VOCs by their chemical properties, subsequent ionization, fragmentation and identification of compounds according to their mass-to-charge ratio. The retention time, which is the time point to reach the end of GC column, differs among VOCs and allows the identification of individual compounds in a mass-spectra library. Disadvantages of GC-MS include its high cost and requiring expert technicians. In addition, GC-MS is not convenient for point-of-care use as it is not portable and do not provide real-time assessment $[55,56]$. Other analytical methods include selected ion flow-tube MS (SIFT-MS), proton-transfer reaction MS (PTR-MS) and ion-mobility spectrometry (IMS) which enable chemical ionization of breath molecules with $\mathrm{H}_{3} \mathrm{O}^{+}$, $\mathrm{NO}^{+}$, or $\mathrm{O}^{2+}$ under very well controlled reactions, hence eliminating the need for a chromatographic process and providing a real-time assessment $[35,55,56]$. Sometimes, they are coupled to multi-capillary columns (MCCs) that allows a separation of complex mixtures more rapidly than GC [35,60]. PTR-MS has the advantage of a higher sensitivity over SIFT-MS. However, both methods are less sensitive in a VOC analysis compared to GC-MS.

\subsubsection{Pattern-Recognition-Based Methods}

E-nose has been utilized as an electronic detection system for breath analysis. It is composed of non-selective sensor arrays detecting VOCs. Sensors produce fingerprints of these compounds according to their chemical and electronic properties. By utilizing the "probabilistic workflow approach", fingerprints are transformed into digital data and processed by several pattern recognition techniques in order to identify breath profiles pertinent to several diseases [58,61]. E-nose has the advantage of being portable and allowing real-time assessment of human breath composition; hence, is likely to have the potential to be translated into point-of-care use in clinical settings. Several studies have shown good sensitivity and specificity with e-nose in discriminating the breath profiles of respiratory diseases from those of healthy subjects [62-64]. The disadvantage of eNose is that it does not allow the identification of specific compounds that would have the role in pathophysiological pathways of diseases. On the other hand, it allows diagnosis and monitoring of diseases based on fingerprints being recognized.

\section{Methods}

\subsection{Search Strategy}

This systematic review was conducted in accordance with Preferred Reporting Items for Systematic Review and Meta-Analysis (PRISMA) guidelines [65]. Search concepts were determined according to the "PECO" strategy (Table 1). An electronic search was carried out using MEDLINE (PubMed), EMBASE and Web of Science databases. Papers published from 2000 to September 2019 were screened. The search strategy consisted of a combination of controlled search words (e.g., Medical Subject Headings/MeSH) and free-text words to specify three search strings: 'mesothelioma', 'pleural mesothelioma', 'malignant pleural mesothelioma' combined with 'exhaled breath', 'breath tests', 'gas chromatography', 'mass spectrometry', 'exhaled breath condensate', 'breathomics', 'proteome', 'phosphoproteomics', 'proteomics' (inception until September 2019). Search terms were modified and proper MeSH terms were selected with the help of a librarian in KU Leuven. In addition, the reference lists of selected articles were checked for any additional studies to include. A methodological filter was not applied. The complete search strategy is presented in Table S1 in the Supplementary Section. 
Table 1. PECO worksheet.

\begin{tabular}{cc}
\hline Population & Malignant Pleural Mesothelioma Patients (MPM) \\
\hline Exposure & Asbestos exposure \\
MPM patients & versus \\
Comparison & Asbestos exposed asymptomatic subjects (AEx) \\
& Subjects with benign asbestos related diseases (ARD) \\
Outcome & Healthy controls (HC) \\
& Exhaled breath profiles in MPM compared with that of (AEx, ARD, HC) \\
\hline
\end{tabular}

Note: MPM—malignant pleural mesothelioma; AEx—asbestos exposed; ARD—asbestos related benign diseases; HC-healthy controls.

\subsection{Study Selection}

The titles and abstracts of the studies that are pertinent to search terms were retrieved and screened by two independent authors (Z.N.T and M.G.) against eligibility criteria. Studies were included if they met the following criteria:

1. Studies in English

2. Studies on human samples

3. Studies that included pleura biopsy confirmed MPM patients

4. Studies that assessed diagnostic accuracy of exhaled breath methods in diagnosis and/or prognosis of MPM. Studies were excluded if a diagnostic marker discovery was performed only in biofluids other than exhaled breath.

Review articles, meta-analyses, case reports, case series, meeting reports and conference abstracts were excluded.

\subsection{Data Extraction and Synthesis}

The full texts of selected studies were reviewed by two independent authors (Z.N.T. and M.G.). Any discrepancies were resolved through discussion and if required, a third reviewer (L.G.) was involved.

Descriptive data regarding: (1) Study details (date of study, title, author and research question) (2) Methods (study design, exposure, primary outcome, potential confounders and any other outcomes) (3) Patient population (population demographics, sample size, inclusion and exclusion criteria) (4) Exposure assessment method (5) Type of exhaled breath analysis (identification of VOC constituents via analytical methods, sensor-based pattern recognition technology, proteomics expressions via exhaled breath condensate) (6) Sensitivity, specificity, area under the receiver operating characteristics (ROC) curves of diagnostic approaches were extracted and recorded on excel sheets dedicated to each study. (7) Sensitivity and specificity rates were grouped according to VOC approaches and forest plots were generated using Review Manager version 5.3. (The Cochrane Collaboration, Copenhagen, Denmark) [66].

\subsection{Quality Assessment}

The quality of articles regarding their observational study design was evaluated using the Newcastle-Ottawa Scale (NOS) [67]. NOS is a tool developed for the quality assessment of non-randomized studies. It has three main domains concerning the "selection" of the study groups, "comparability" and "exposure assessment" of cases and controls. Each domain includes numbered items and evaluation is based on the allocation of a star $\left(^{*}\right)$ to each item, indicating favorable judgement. We modified the comparability domain considering age, sex, smoking status and the presence of additional systemic conditions that would affect constituents of exhaled breath. In addition, we added exposure information from company records into the "ascertainment of exposure" item. Selection and 
exposure domains can be awarded with a maximum of four and three stars, respectively, while the comparability domain can be awarded with a maximum of two stars. An overall score of $\geq 7$ defined high quality, 4-7 fair quality, and 0-3 poor quality.

\section{Results}

In total, 386 records compatible with the search terms were identified through the MEDLINE, EMBASE and Web of Science databases. These records were subsequently exported to Endnote X9 (Philadelphia, PA, USA) [68]. Ten additional records were identified through reference lists of relevant articles. A total of 368 of them remained for title and abstract screening after duplicates were excluded. Studies that did not meet the inclusion criteria were excluded during title and abstract screening and thirty-nine were closely assessed for eligibility. Of these thirty-nine records, sixteen review articles, seven meeting abstracts and one book chapter were excluded. One study was excluded because it solely investigated serum biomarkers of MPM. The remaining eight studies did not cover MPM patients, although they assessed exhaled breath analysis of asbestos related diseases. Six studies [69-74] were eventually included in the review. An overview of the study selection steps is presented in Figure 3.

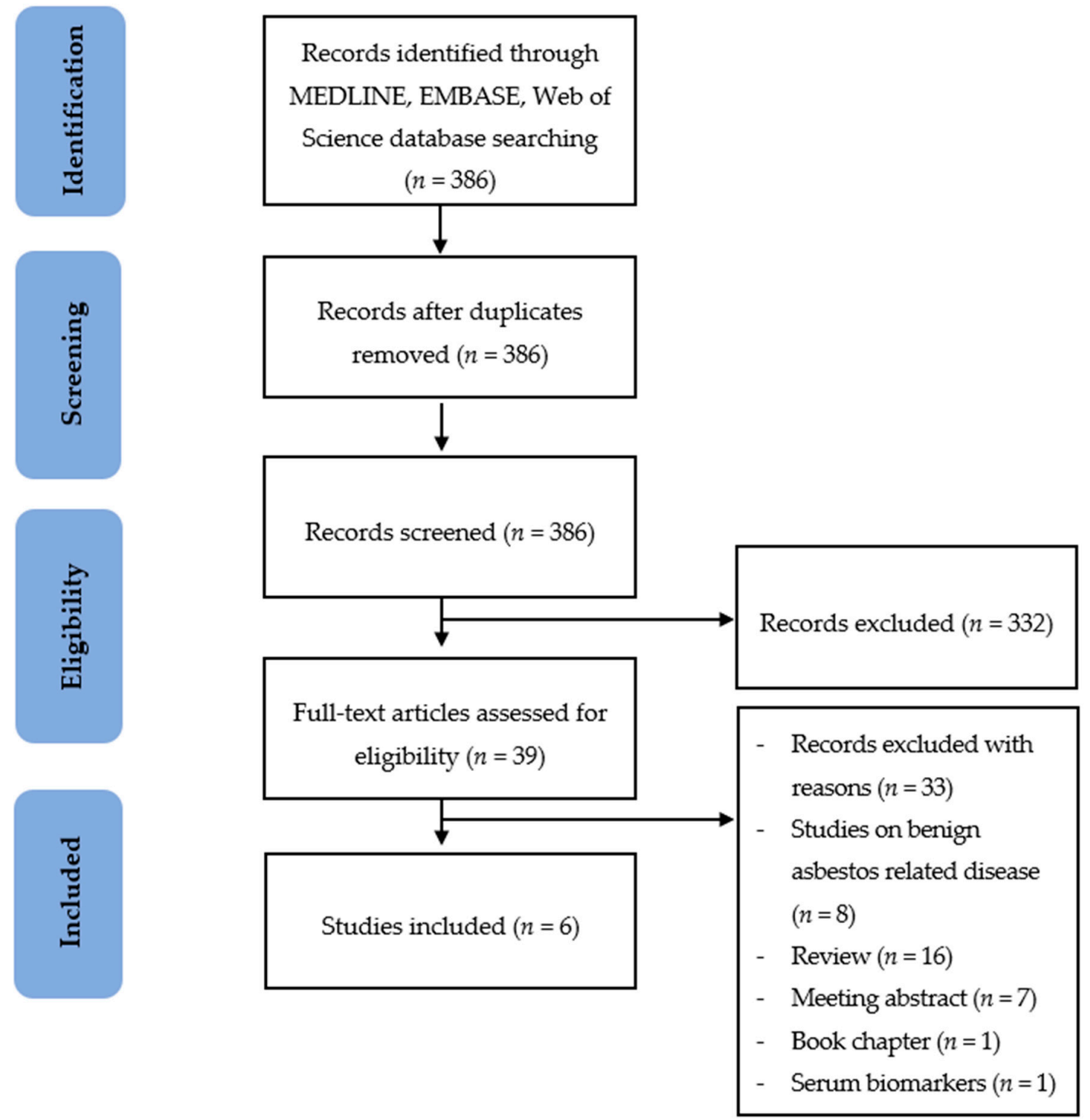

Figure 3. Flow chart of the study selection process. 


\subsection{Quality Assessment of Studies}

The overall quality scores of studies ranged from 4 to 6 (out of 9), indicating fair quality. Representative samples of MPM cases were recruited from respiratory and occupational medicine departments of several hospitals, in all the studies. Control groups were selected from volunteers working at hospitals [69,70], from the patients visiting outpatient settings [72-74] or from community volunteers [71]. Cases and controls were matched for age, sex and smoking status in one study [71]. Three studies excluded subjects with any systemic disease or respiratory infection [69-71]. Information regarding asbestos exposure of MPM cases were obtained through self-reports [69,70] or questionnaires [71-74] while that of asbestos exposed control groups were mainly retrieved from company records $[69,70,72-74]$. However, none of the studies obtained asbestos exposure information through structured exposure assessment tools nor accounted for duration of asbestos exposure. Moreover, none of the studies ensured blindness of the investigators. The results of the NOS scores of the included studies are presented in Table 2. In addition, the details of the quality assessment are presented in Table S2 in the Supplementary Section.

Table 2. Quality assessment of the selected studies.

\begin{tabular}{ccccc}
\hline Study & $\begin{array}{c}\text { Selection } \\
(/ 4)\end{array}$ & $\begin{array}{c}\text { Comparability } \\
(/ 2)\end{array}$ & $\begin{array}{c}\text { Exposure } \\
(/ 3)\end{array}$ & $\begin{array}{c}\text { Overall Score } \\
(/ 9)\end{array}$ \\
\hline $\begin{array}{c}\text { Gennaro et al. } \\
\text { (2010) [69] }\end{array}$ & 3 & 1 & 1 & 5 \\
\hline $\begin{array}{c}\text { Dragonieri et al. } \\
\text { (2011) [70] }\end{array}$ & 3 & 1 & 1 & 5 \\
\hline $\begin{array}{c}\text { Chapman et al. } \\
\text { (2012) [71] }\end{array}$ & 4 & 1 & 1 & 5 \\
\hline $\begin{array}{c}\text { Lamote et al. } \\
\text { (2016) [72] }\end{array}$ & 3 & 1 & 1 & 5 \\
\hline $\begin{array}{c}\text { Lamote et al. } \\
\text { (2017) [73] }\end{array}$ & 3 & 1 & 1 & 4 \\
\hline $\begin{array}{c}\text { Lamote et al. } \\
(2017) \text { [74] }\end{array}$ & 3 & 0 & 1 & 2 \\
\hline
\end{tabular}

\subsection{Study Characteristics}

All studies were of a cross-sectional, case-control design, published between 2010 and 2017, and explored VOC-based exhaled breath profile in MPM patients using analytical or sensor-based technologies. Four studies [71-74] were conducted at more than one center. The number of MPM cases varied between 13 and 52 across studies. All MPM diagnosis were confirmed by pleural biopsy. In addition, a group of pathology panel was asked for independent confirmation in three studies [72-74], which conformed to international guidelines [75]. Control groups composed of asbestos-exposed workers (AEx) and never asbestos-exposed healthy individuals (HC). Five studies [69-71,73,74] included subjects with benign asbestos-related diseases (ARD). In addition to AEx and ARD controls, the breath profiles of MPM patients were compared with those of lung cancer (LC) and non-asbestos-related benign lung disease (BLD) patients in one study [74]. Two studies [70,71] mentioned MPM stages, most of which were Stage II or III (24 out of 33 subjects). Histopathologic subtypes were mentioned in two studies [70,74]. However, owing to the small sample sizes, none of the studies evaluated VOC changes in different subtypes or stages of MPM. The summary of individual articles is presented in Tables 3 and 4 . 
Table 3. Overview of the studies regarding study type and the exhaled breath sampling method.

\begin{tabular}{|c|c|c|c|c|c|}
\hline Study & Study Type & $\begin{array}{l}\text { Population } \\
(n, \text { Age })\end{array}$ & $\begin{array}{l}\text { Breath Collection } \\
\text { Method }\end{array}$ & Alveolar/Total Breath & Adjustment for Ambient Air and Collector \\
\hline Gennaro (2010) [69] & Cross-sectional, case-control & $\begin{array}{l}\operatorname{MPM}(13,60.9 \pm 12.2 \mathrm{y}) \\
\operatorname{AEx}(13,67.2 \pm 9.8 \mathrm{y}) \\
\operatorname{HC}(13,52.2 \pm 16.2 \mathrm{y})\end{array}$ & $\begin{array}{l}\text { Tidal breathing ( } 5 \mathrm{~min} \text { ) followed by VC } \\
\text { maneuver Tedlar bag }\end{array}$ & Total breath & $\begin{array}{l}\text { Inspiratory VOC filter, Background VOC } \\
\text { concentration in a clean Tedlar bag }\end{array}$ \\
\hline Dragonieri (2011) [70] & Cross-sectional, case-control & $\begin{array}{l}\operatorname{MPM}(13,61 \pm 12 \mathrm{y}) \\
\operatorname{AEx}(13,67 \pm 10 \mathrm{y}) \\
\operatorname{HC}(13,52 \pm 16 \mathrm{y})\end{array}$ & $\begin{array}{c}\text { Tidal breathing } \\
\text { (5 min) followed by VC maneuver10 L } \\
\text { Tedlar bag }\end{array}$ & Total breath & $\begin{array}{l}\text { Inspiratory VOC filter, Background VOC } \\
\text { concentration in a clean Tedlar bag }\end{array}$ \\
\hline Chapman (2012) [71] & Multicenter, cross-sectional, case-control & $\begin{array}{c}\text { MPM }(20,69 \pm 10 \mathrm{y}) \\
\text { Asbestosis }(5,70 \pm 10.5 \mathrm{y}) \\
\text { BLD }(13,70.9 \pm 8.2 \mathrm{y}) \\
\text { HC }(42,66.5 \pm 14 \mathrm{y})\end{array}$ & $\begin{array}{l}\text { Tidal breathing ( } 5 \mathrm{~min} \text { ) followed by VC } \\
\text { maneuver } 2 \mathrm{~L} \text { gas impermeable bag }\end{array}$ & Total breath & - \\
\hline Lamote (2016) [72] & Multicenter, cross-sectional, case-control & $\begin{array}{l}\text { MPM }(23,66(59-73) \text { y) } \\
\text { AEx }(22,56(55-57) \text { y) } \\
\text { HC }(21,56(40-58) \text { y) }\end{array}$ & Tidal breathing ( $3 \mathrm{~min})$ & Alveolar breath & $\begin{array}{l}10 \mathrm{~mL} \text { of ambient air sampled as background, } \\
\text { alveolar gradients of VOCs were calculated }\end{array}$ \\
\hline Lamote (2017) [73] & Multicenter, cross-sectional, case-control & $\begin{array}{c}\text { MPM }(14,69(65-73) \text { y) } \\
\text { AEx }(19,50(49-53) \text { y) } \\
\text { ARDs }(15,60(58-63) \text { y) } \\
\text { HC }(16,56(52-59) \text { y) }\end{array}$ & $\begin{array}{l}\text { Tidal breathing }(5 \mathrm{~min}) \text { followed by VC } \\
\text { maneuver } 10 \mathrm{~L} \text { Tedlar bag }\end{array}$ & Total breath & $\begin{array}{l}\text { VOC filter Before sampling; Tenax tubes } \\
\text { were being flushed with helium }\end{array}$ \\
\hline Lamote (2017) [74] & Multicenter, cross-sectional, case-control & $\begin{array}{c}\text { MPM }(52,67(62-72) \text { y) } \\
\operatorname{AEx}(59,53(50-55) \text { y) } \\
\operatorname{ARD}(41,58(55-62) \text { y) } \\
\operatorname{BLD}(70,58(40-68) \text { y) } \\
\operatorname{HC}(52,51(34-56) \text { y) }\end{array}$ & Tidal breathing ( $3 \mathrm{~min})$ & Alveolar breath & $\begin{array}{l}\text { Disposable mouthpieces and filters Alveolar } \\
\text { gradients of VOCs were calculated }\end{array}$ \\
\hline
\end{tabular}

Note: Mean [69-71], Median [72-74]. y-year; MPM-malignant pleural mesothelioma; AEx—asbestos exposed; HC—healthy controls; ARD—asbestos related benign diseases; BLD—non-asbestos related benign lung diseases-LC—lung cancer; VC—vital capacity VOC-volatile organic compounds. 
Table 4. Overview of studies regarding breath detection and statistical methods used.

\begin{tabular}{|c|c|c|c|c|}
\hline Study & $\begin{array}{c}\text { Breath Profile } \\
\text { Detection Method }\end{array}$ & Pre-Treatment & Statistics & Results \\
\hline Gennaro (2010) [69] & GC-MS & $\begin{array}{c}\text { Adsorbtion on thermal } \\
\text { desorption (TD) sorbent cartridge }\end{array}$ & $\begin{array}{l}\text { Shapiro-Wilk tests, ANOVA, PCA, } \\
\text { DFA, CP-ANN }\end{array}$ & $\begin{array}{l}\text { Cyclohexane able to discriminate MPM from HC and AEx } \\
\text { Cyclopentane able to discriminate AEx from MPM and HC }\end{array}$ \\
\hline Dragonieri (2011) [70] & E-nose & - & PCA, CDA & 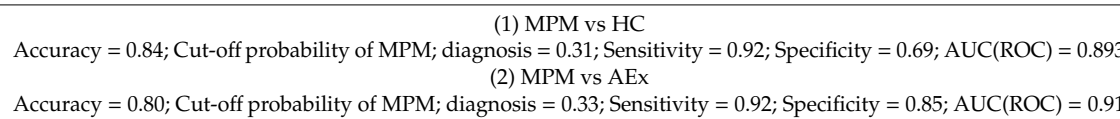 \\
\hline Chapman (2012) [71] & E-nose & - & $\begin{array}{l}\text { PCA, CDA, } \\
\text { M-distance }\end{array}$ & $\begin{array}{c}\text { (1) MPM vs HC } \\
\text { Accuracy }=0.95 ; \text { Sensitivity }=0.90 ; \text { Specificity }=0.91 \\
\text { (2) MPM vs ARD } \\
\text { Sensitivity }=0.90 ; \text { Specificity }=0.83 \\
\text { (3) MPM vs ARD vs HC } \\
\text { Sensitivity }=0.90 ; \text { Specificity }=0.83\end{array}$ \\
\hline Lamote (2016) [72] & MCC-IMS & - & $\begin{array}{l}\text { Chi-square/ Fisher's exact, } \\
\text { Kolmogorov-Smirnov, } \\
\text { T-test/ANOVA, } \\
\text { Wilcoxon-Mann-Whitney/ } \\
\text { Kruskal-Wallis, Logistic regression } \\
\text { using the least absolute shrinkage } \\
\text { and selection operator (lasso) } \\
\end{array}$ & 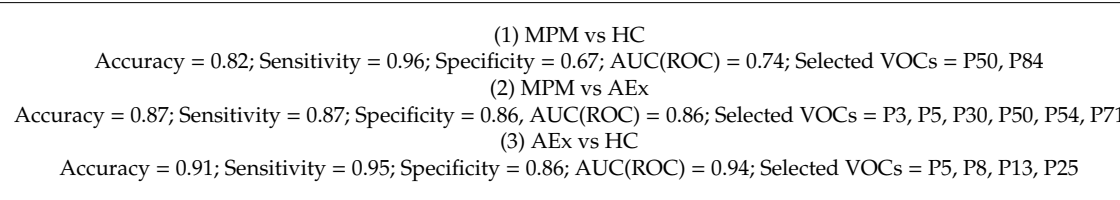 \\
\hline Lamote (2017) [73] & GC-MS, E-nose & $\begin{array}{l}\text { Adsorbtion onto Tenax GR } \\
\text { sorbent tubes, Thermal } \\
\text { desorption (TD) }\end{array}$ & $\begin{array}{l}\text { Pearson's Chi-square, } \\
\text { Shapiro-Wilk, Lasso regression } \\
\text { (applied to GC-MS data), PCA } \\
\text { (applied to e-nose data) }\end{array}$ & 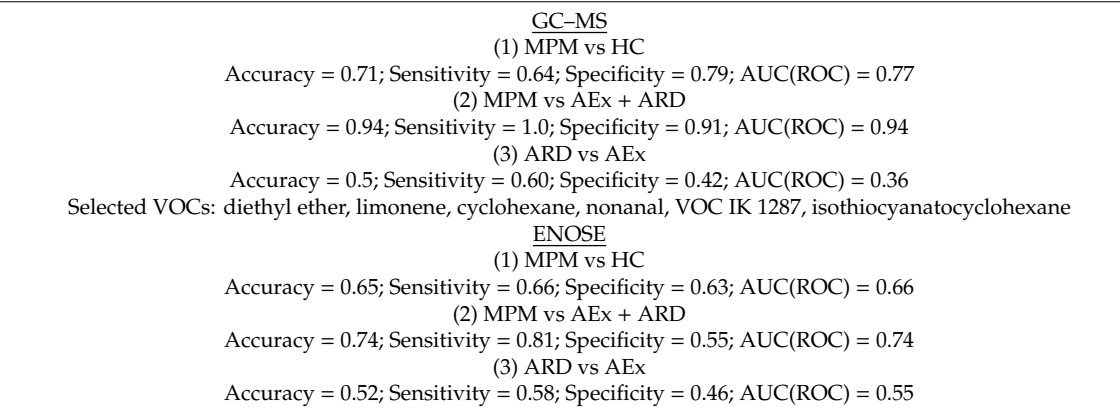 \\
\hline Lamote (2017) [74] & MCC-IMS & - & $\begin{array}{l}\text { Fisher's exact, } \\
\text { Kolmogorov-Smirnov, ANOVA, } \\
\text { Kruskal-Wallis }\end{array}$ & 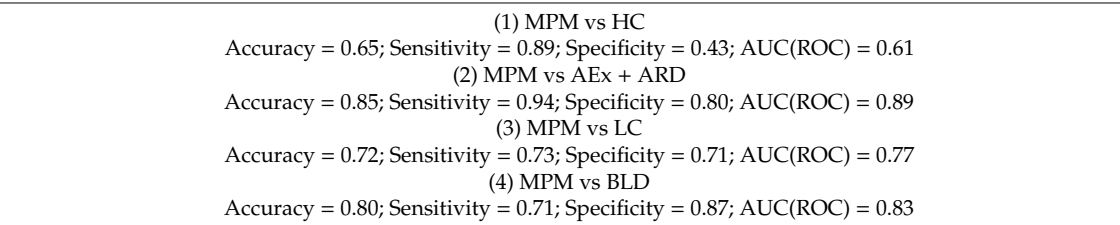 \\
\hline
\end{tabular}

Note: GC-MS— Gas Chromatography Coupled to Mass Spectrometry; MPM—malignant pleural mesothelioma; AEx—asbestos exposed; HC—healthy controls; ARD—asbestos related benign diseases, BLD—non-asbestos related benign lung diseases; LC—lung cancer; VOC—volatile organic compounds; AUC—area under curve; ROC—receiver operating characteristics. 
The forest plots for the sensitivity and specificity of VOC methods in distinguishing MPM from healthy controls showed that sensitivity $(95 \% \mathrm{CI})$ changed between $0.62(0.32-0.86)$ and $0.96(0.78-1.0)$ across studies while specificity was between $0.42(0.29-0.57)$ and $1.0(0.74-1.0)$. Similarly, sensitivity to distinguish MPM from asbestos-exposed subjects was between $0.62(0.32-0.86)$ and $0.96(0.78-1.0)$ while specificity was $0.52(0.32-0.71)$ and $1.0(0.74-1.0)$. We observed heterogeneity across studies by comparing confound intervals visually. However, meta-analytic approaches (i.e., hierarchichal summary ROC, bivariate models, meta-regression) to pool diagnostic accuracy of studies and to address sources of heterogeneity, were not conducted due to the small sample sizes and the small number of studies under each VOC method (Figures 4 and 5).
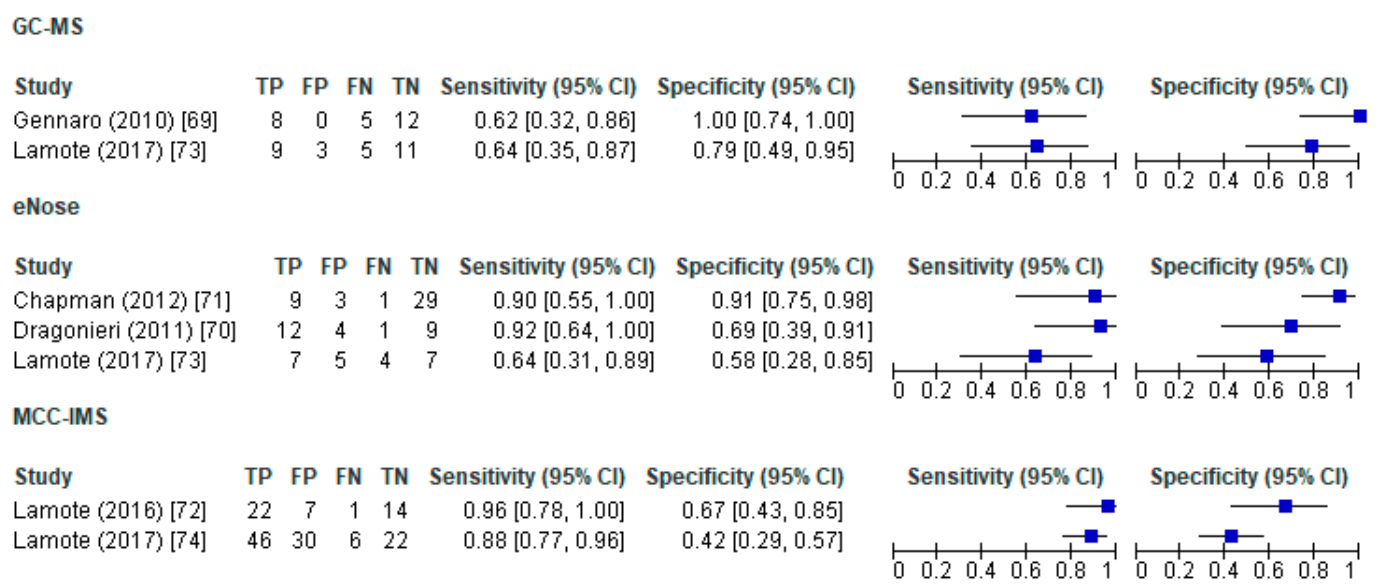

Figure 4. Forrest plots for sensitivity and specificity of VOC methods in distinguishing MPM from healthy controls. VOC-volatile organic compound; GC-MS—gas chromatography-mass spectrometer; MCC-IMS - multi-capillary column-ion mobility spectrometer; TP—true positives; $\mathrm{FP}$-false positives; FN—false negatives; $\mathrm{TN}$-true negatives; $\mathrm{CI}$-confidence interval.
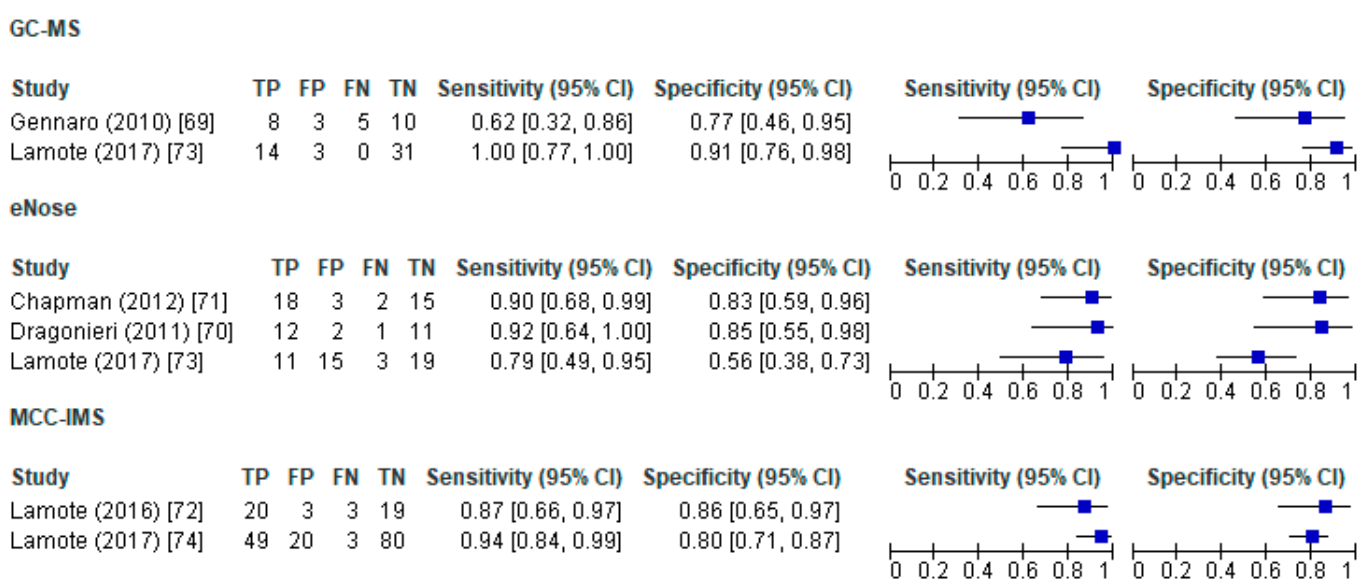

Figure 5. Forrest plots for sensitivity and specificity of VOC methods in distinguishing MPM from asbestos exposed. VOC—-volatile organic compound; GC-MS—gas chromatography-mass spectrometer; MCC-IMS - multi-capillary column-ion mobility spectrometer; TP—true positives; FP—false positives; $\mathrm{FN}$-false negatives; $\mathrm{TN}$-true negatives; $\mathrm{CI}$-confidence interval.

\subsection{Exhaled Breath Collection and Analysis Methods}

\subsubsection{Gas Chromatography Coupled to Mass Spectrometry (GC-MS)}

GC-MS was used as the analytical approach in two studies [69,72]. Gennaro et al. [69] tested the diagnostic accuracy of exhaled breath by using GC-MS in MPM diagnosis. Thirteen subjects 
with histologically proven MPM, 13 long-term asbestos-exposed subjects with radiologically proven benign pleural disease and 13 healthy subjects never exposed to asbestos were involved in the study. Breath samples were collected inside Tedlar ${ }^{\circledR}$ bags after tidal breathing and a vital capacity maneuver. An inspiratory VOC-filter (A2, North Safety, Middelburg, The Netherlands) was used in order to reduce the contamination of ambient air. In addition, potential VOC emissions from the clean bags were accounted by monitoring background VOC concentrations inside clean Tedlar ${ }^{\circledR}$ bags. The air inside Tedlar ${ }^{\circledR}$ bags was pumped into sorbent cartridges composed of a cylindrical stainless-steel net with an external diameter of $4.8 \mathrm{~mm}$, containing Carboxen 1003, Carbopack B and carbopack $\mathrm{Y}$ as adsorbent bad (Sigma Aldrich, Milano, Italy), subsequently. After thermal desorption of the cartridges by a thermal desorber (Markes International Ltd., Unity ${ }^{\mathrm{TM}}$, Llantrisant, UK) equipped with an autosampler (Markes mod. ULTRA ${ }^{\mathrm{TM}}$ ), the samples were analyzed by gas chromatography (Agilent GC-6890 PLUS) and a mass selective detector (Agilent MS-5973 N). The discriminant function analysis (DFA) shows that MPM patients showed higher concentrations of cyclohexane (median value $=251.79 \mathrm{ng} / \mathrm{L}$ ) compared to subjects with long-term exposure to asbestos (median value $=69.31 \mathrm{ng} / \mathrm{L}$ ) and healthy controls (median value $=33.08 \mathrm{ng} / \mathrm{L}$ ), while cyclopentane was the dominant compound in the discrimination of asbestos exposed from MPM and healthy controls. They also showed the compounds that arise from the collector bags (i.e., DMCA, phenol).

Six years later, Lamote et al. [72] recruited 14 treatment naïve MPM patients, 15 patients with benign asbestos-related diseases, 19 asbestos-exposed asymptomatic persons and 16 healthy controls in order to test the hypothesis that VOC patterns in exhaled breath would differ between MPM patients, asbestos-exposed and asbestos-unexposed subjects. They used GC-MS and e-nose for the breath analysis. Subjects breathed tidally into a two-way non-breathing valve (Hans Rudolph 2700, Hans Rudolph Kansas City, USA) during $5 \mathrm{~min}$ and exhaled full vital capacity volume into the 10L Tedlar ${ }^{\circledR}$ bag, subsequently. An inspiratory VOC-filter (A2, North Safety, Middelburg, The Netherlands) was used to reduce the effect of exogenous VOCs. An amount of $500 \mathrm{ml}$ of sample inside the bag was transferred to a sorbent tube ( 3.5 “long, 0.25 “outer diameter) filled with $200 \mathrm{mg}$ Tenax ${ }^{\circledR}$ GR (35/60 mesh; Merkes International Ltd., Llantrisant, UK), subsequently. Sorbent tubes were dry purged and breath samples were thermally desorbed using a Unity Series 2 Thermal Desorption system (Markes, Llantrisant, UK) coupled to GC-MS (thermo Finnigan, Austin, TX, USA). Diethyl ether, limonene, nonanal, methylcyclopentane and cyclohexane were found to be dominant VOCs to discriminate asymptomatic asbestos exposed from MPM, with an accuracy rate of 0.97 . In addition, the GC-MS analysis was able to discriminate MPM patients from the pooled group of asymptomatic asbestos-exposed and benign asbestos disease patients with an accuracy of 0.94 .

\subsubsection{Ion Mobility Spectrometry Coupled to Multi-capillary Columns (IMS-MCC)}

Breath Discovery ion mobility spectrometry (IMS) coupled to a multi-capillary column (MCC) method was used in two studies of the same research group [72,74]. In the first study [71], Lamote et al., investigated VOCs in exhaled breath of 23 MPM patients and compared the findings with those of 22 asymptomatic former asbestos exposed workers and 21 healthy asbestos non-exposed subjects. In both studies, breath samples were collected by a SpiroScout ultrasound-controlled breath sampler (Ganshorn Meizin Electronic, Niedelauer, Germany) connected to a BioScout breath analyzing device operating on VOCan v2.4 software (B\&S Analytik, Dortmund, Germany). Alveolar air was sampled via monitoring $\mathrm{CO}_{2}$ levels in exhaled breath by the volumetric capnography method. Breath analytes initially passed within a non-polar OV-5 MCC column (Multichrom Ltd., Novobirsk, Russia), depending on their chemical properties. Pre-separated analytes were transferred to the ionization chamber where they became positively charged from prior-ionized carrier gas ( $\alpha 1$-notrogen gas, Air Liquide Medical, 99.999\% pure, CAS-no: 7727-37-9, Schelle, Belgium). Carrier gas was ionized by $95 \mathrm{MBq} 63 \mathrm{Ni}$ $\beta$-radiation source and ionized molecules accelerated within an electrical field along the drift region. They eventually elicited an electrical current on a Faraday plate detector, leading to VOC peak intensity which was subsequently cross-checked with an IMS-MCC database. 
MPM patients were discriminated from both former asbestos-exposed and non-exposed healthy controls with an $87 \%$ sensitivity, a $70 \%$ specificity, and positive and negative predictive value of $61 \%$ and $91 \%$, respectively. In addition, asbestos-exposed individuals could be discriminated from MPM patients with $87 \%$ sensitivity, $86 \%$ specificity, PPV and NPV of $87 \%$ and $86 \%$, respectively. One year later, they aimed to validate the findings of the previous study in a larger population including subjects with different conditions. They were able to discriminate MPM from pooled group of asbestos exposed and benign asbestos-related diseases with a sensitivity of $95 \%$ and NPV of $96 \%$ [74]. They were also able to discriminate MPM from benign lung diseases and lung cancer with an accuracy of $80 \%$ and $72 \%$, respectively.

\subsubsection{Sensor-Based Technologies (Electronic Nose)}

An exhaled breath analysis was conducted by e-nose technology in three studies $[70,71,73]$. Dragonieri et al. [70] included 13 MPM, 13 subjects with previous long-term asbestos exposure history and 13 healthy control subjects and tested whether VOCs were able to discriminate MPM patients from asbestos-related benign pleural diseases and healthy controls. Patients breathed tidally into a non-breathing valve connected to an inspiratory VOC-filter (A2, North Safety, The Netherlands) and to a silica-filled drying chamber for $5 \mathrm{~min}$. They subsequently performed a forced expiratory maneuver and exhaled into a Tedlar ${ }^{\circledR}$ bag connected to Cyranose 320 device (Smiths Detections, Pasadena, CA, USA) containing a nanocomposite array with 32 sensors, each of which responds to exhaled breath by changing electrical resistance leading to unique breath prints. They found that MPM patients were discriminated from asbestos exposed subjects with a cross-validated accuracy (CVA) of $80.8 \%$, a sensitivity of $92.3 \%$ and a specificity of $85.7 \%$. Moreover, breath prints were able to differentiate MPM from healthy controls with a CVA of $84.6 \%$. Chapman et al. [71] used carbon polymer assay (CPA) e-nose (Cyranose 320, Smiths Detections, Pasadena, CA, USA) to distinguish patients with MPM, asbestosis, benign asbestos-related pleural disease and healthy controls. They set up a two-phase study composed of a training and a validation phase conducted on different subjects. They collected breath samples into a 2-L gas impermeable bag (Rapak, Mulgrave, Australia), following tidal breathing and forced vital capacity maneuvers. However, a nose clip or VOC filter was not used during breath collection. The results showed that the breath prints of MPM patients were distinguished from those of control subjects with an accuracy of $95 \%$. In addition, 38 out of 42 subjects were identified correctly in the validation phase. They concluded that for breath print identification between MPM, asbestos-related diseases, and healthy controls, CPA e-nose had a sensitivity of $90 \%$, a specificity of $88 \%$, a positive and negative predictive value of $60 \%$ and $97.8 \%$, respectively. Lamote et al. [73] aimed to assess the accuracy of e-nose as well as that of GC-MS in MPM screening. Patients breathed tidally for $5 \mathrm{~min}$ and exhaled to their vital capacity into Tedlar ${ }^{\circledR}$ bags. An amount of $500 \mathrm{~mL}$ of breath sample was adsorbed into a Tenax GR tube (Tenax GR SS $6 \mathrm{~mm}$ x 7" (CAMSCO, Houston, Texas, USA) and thermally desorbed, subsequently. Four different e-nose devices were used in the analysis (Cyranose C320, Tor Vergata eNose, Common Invent eNose, Owlstone Lonestar). Sensor signals introduced by four devices were combined to establish breath profiles. The e-nose technique was able to discriminate MPM from asbestos-exposed individuals (including asymptomatic and benign asbestos related disease patients) with $74 \%$ accuracy. In addition, they found sensitivity, specificity, positive and negative predictive values of e-nose in discriminating MPM from asbestos-exposed individuals of $0.82,0.55$, 0.82 and 0.55 , respectively.

\subsection{Statistical Methods Used in Studies}

\subsubsection{GC-MS Studies}

Gennaro et al. [69] applied a variance analysis (ANOVA) on normalized data to find the compounds showing statistically significant difference in the exhaled breath of MPM, asbestos-exposed and healthy controls. A principal component analysis (PCA) and a discriminant function analysis (DFA) were used 
to find the greatest variance within data (PCA) and to find which variable discriminates between two or more groups (DFA). Statistica for Windows v. 6.1.144.0 (StatSoft Italia srl, Vigonza, Italy) was used for the analysis. In addition, counter propagation artificial neural networks (CP-ANN) were applied to data in order to obtain the best classification performance.

Lamote et al. [73] used the least absolute shrinkage and selection operator (lasso) regression analysis (glmnet R package v2.0-2) to find the VOCs that have the most discriminative power for distinguishing MPM from healthy controls as well as the number of times VOCs were selected. Model-predicted outcomes were used to construct an ROC curve (ROCR R-package- v1.0-7) and estimate sensitivity, specificity, positive and negative predictive values (PPV, NPV), the diagnostic accuracy of the final model, and the area under the receiver operating characteristics AUC(ROC).

\subsubsection{IMS-MCC Studies}

Raw data were processed by VisualNow v3.7 software (B\&S Analytik, Dortmund, Germany), resulting in a list of VOC-peak intensities, in the two studies of Lamote et al. [72,74]. Due to the high number of variables and the low number of samples, they decided to use the lasso regression model (glmnet R-package). Model-predicted outcomes of all the patients were used to build a ROC curve (ROCR R-package- v1.0-7) and to estimate the sensitivity, specificity, positive and negative predictive values (PPV, NPV), and diagnostic accuracy of the final model and the AUC(ROC). In addition, the alveolar gradient of each VOC was calculated and added as a predictor in the model.

\subsubsection{E-nose Studies}

In the study of Dragonieri et al. [70], raw data produced by sensors were analyzed by SPSS software version of 16.0 (SPSS Inc., Chicago, IL, USA). A t-test was used in order to select the principal components that are discriminative between the subject groups. Principal components were fit in a canonical discriminant analysis (CDA), subsequently to creating a model giving the maximum variance between groups and the minimum variance within the groups. The sensitivity, specificity, positive and negative predictive values as well as a ROC curve were developed on the basis of the canonical discriminant function. The cross-validated accuracy (CVA) percentage was calculated to find the agreement between the clinical and model-based classifications.

Chapman et al. [71] also used principal component reduction and CDA and calculated CVA to find the accuracy of breath prints that were discriminative of different groups.

\section{Discussion}

We identified six studies through our search criteria. The results regarding the accuracy of exhaled breath VOCs in discriminating MPM from healthy controls, as well as from asbestos-exposed individuals are encouraging. Gennaro et al., and Lamote et al. $[69,73]$ reported that cyclohexane was able to discriminate MPM from the healthy subjects. Gennaro et al. [69] related this finding with the hypothesis of a relationship between reactions of xenobiotic agents' degradation and the neoplastic processes $[76,77]$ as cyclohexane is a metabolite of $\varepsilon$-caprolactam. Cyclohexane has also been proposed to be indicative of oxidative stress in the exhaled breath of lung cancer and colorectal cancer patients $[78,79]$. However, the exact mechanism underlying its endogenous origin is still not clear. Gennaro et al. [69] also found that cyclopentane was able to discriminate long-term asbestos-exposed subjects from MPM and healthy controls, concluding that it can be used as a screening marker in asbestos-exposed individuals. Similarly, Dragonieri et al. [70] and Chapman et al. [71] reported that e-nose was able to detect breathprints distinguishing MPM patients from asbestos exposed individuals. However, pattern-recognition techniques do not identify individual compounds but rather allow the recognition of the overall composition of VOCs. In addition, e-nose has a lower sensitivity compared to the gold standard GC-MS $[73,80]$. Lamote et al. [72,74] found a high sensitivity and NPV of VOC profiles (i.e., P3, P5, P50, P71) in discriminating MPM from asbestos-exposed subjects detected by IMS-MCC technique which supports the idea of using breath tests as a screening tool to discriminate 
MPM from former asbestos workers under the risk of developing MPM. However, the small sample size restricted researchers in identifying the possible molecular discriminators within the compounds and thus in interpreting the mechanisms underlying MPM pathogenesis.

Although studies have shown promising results, we recognized some limitations regarding their qualities. First, all the studies were carried on small groups, which is likely to limit the internal validity of the methods as well as the generalizability of the findings to the population. All the studies involved histologically proven MPM cases which was in accordance with the global guidelines. However, there were heterogeneities among the control groups in terms of the selection of the subjects. For instance, cases and controls were not matched for age in some studies $[69,70,73,74]$. Nevertheless, it is difficult to find healthy, age-matched controls of MPM cases since most patients are diagnosed at old ages. Moreover, the effect of age on breath composition is not clear, as studies show conflicting results $[71,81,82]$. Similarly, the smoking status of cases and controls was altered among studies; for example, current smokers were excluded in two studies [70,71], cases and controls were matched for smoking status in one study [71], while in others, they were not excluded nor accounted for [72-74]. Lamote et al. [72] evaluated the predictive value of smoking and gender to discriminate MPM from asbestos-exposed and healthy controls by generalized linear model, yet smoking was not selected in the final model, indicating that it is not predictive of MPM even in asbestos-exposed population. Although smoking is not a cause of MPM, it has been well established that it may alter VOC composition in exhaled breath $[82,83]$. In addition to the exogenous compounds taken in by the inhalation of tobacco smoke, smoking may also induce oxidative stress-related changes leading to the production of endogenous VOCs. In light with those findings, we support the idea that VOC profiles should be further investigated in asbestos workers as their smoking rates are high [73].

In two studies [70,71], the control groups were selected from volunteers working in a hospital and in a university. Healthcare professionals are reported to be exposed to several VOCs, depending on occupation and work locations [84,85], although compelling evidence on exogenous VOCs from hospital environments contributing to the exhaled breath profiles of healthcare workers is hardly available. Despite the fact that there is no indication in the studies of de Gennaro et al. [70] and Dragonieri et al. [71] on exogenous exposure related with the hospital environment, we temperately recommend recruiting control groups that are not healthcare workers.

Through our search strategy, we did not identify any studies regarding EBC in MPM patients. As such, EBC biomarkers were investigated in asbestos-exposed individuals in a limited number of studies. Chow et al. [46] reported elevated oxidative stress and inflammatory markers in asbestosis patients, but not in individuals with pleural diseases. Considering asbestosis increases the risk for developing MPM, we believe that EBC should be deeply investigated in MPM with regards to oxidative stress and inflammatory pathway mechanisms.

A limitation of our study is that we could not conduct a meta-analysis of the diagnostic accuracy as the small number of studies restricted us to address possible heterogeneity among studies using rigorous statistical methods.

\section{Conclusions}

MPM is the primary cancer of pleura associated with past asbestos exposure and recent reports predict an increase in incidence and mortality rates. Difficulties in diagnosing MPM at early stages lead to poor clinical outcome. Hence, significant efforts have been devoted to investigating serum and tissue biomarkers of MPM over the last two decades. As summarized in this review, research on exhaled breath biomarkers of MPM is at its early phases, yet is likely to be promising in the future, as breath is a non-invasive and repeatable way to access numerous biomarkers reflecting human metabolism. GC-MS and IMS-MCC are the analytical methods that have been used to assess VOC profiles in recent studies. Although GC-MS is the gold standard method, IMS-MCC has the advantage that no pre-concentration steps are needed; therefore, it can be utilized for a real-time breath analysis. The studies involved in this review identified some compounds (i.e, cyclohexane, P3, P5, P50, P71, 
diethyl ether, limonene, nonanal, VOC IK 1287) that can be indicative of MPM development in an asbestos-exposed population. Some of them (i.e., P3, P5, P50, P71) are needed to be studied further in terms of their composition in order to provide insights into their association with the MPM mechanism. In addition, VOC profiles should be interpreted carefully, as the respiratory system is the route to many exogenous substances and the elimination of endogenous VOCs may be affected by several individual factors (i.e., physiologic status, smoking, drugs etc.). We believe that exhaled breath studies need to account for the potential confounders that might have an impact on VOC composition. Pattern recognition techniques have also been used in some studies which showed promising results in discriminating MPM from asbestos-exposed and from healthy controls. Although the results on human studies are encouraging, small sample sizes and methodological diversities among studies limit their translation into clinical practice. Furthermore, a great majority of the studies lack external validation. Therefore, more prospective studies with standardized methodologies in line with the most recent guidelines should be conducted and external validation of the results should be tested on larger populations.

Supplementary Materials: The following are available online at http://www.mdpi.com/1660-4601/17/3/1110/s1, Table S1: Search terms, Table S2: Quality assessment of selected studies.

Funding: This research received no external funding.

Acknowledgments: Krizia Tuand, information specialist from the KU Leuven Libraries 2Bergen—Learning Centre Désiré Collen, helped with generation of search strategies.

Conflicts of Interest: The authors declare no conflict of interest.

\section{References}

1. Markowitz, S. Asbestos-related lung cancer and malignant mesothelioma of the pleura: Selected current issues. Semin. Respir. Crit. Care Med. 2015, 36, 334-346. [CrossRef] [PubMed]

2. Bray, F.; Ferlay, J.; Soerjomataram, I.; Siegel, R.L.; Torre, L.A.; Jemal, A. Global cancer statistics 2018: GLOBOCAN estimates of incidence and mortality worldwide for 36 cancers in 185 countries. CA: A Cancer J. Clin. 2018, 68, 394-424. [CrossRef] [PubMed]

3. Mazurek, J.M.; Syamlal, G.; Wood, J.M.; Hendricks, S.A.; Weston, A. Malignant Mesothelioma Mortality-United States, 1999-2015. MMWR Morb. Mortal. Wkly. Rep. 2017, 66, 214-218. [CrossRef] [PubMed]

4. Odgerel, C.-O.; Takahashi, K.; Sorahan, T.; Driscoll, T.; Fitzmaurice, C.; Yoko-O, M.; Sawanyawisuth, K.; Furuya, S.; Tanaka, F.; Horie, S.; et al. Estimation of the global burden of mesothelioma deaths from incomplete national mortality data. Occup. Environ. Med. 2017, 74, 851-858. [CrossRef] [PubMed]

5. Wagner, J.C.; Sleggs, C.A.; Marchand, P. Diffuse pleural mesothelioma and asbestos exposure in the North Western Cape Province. Occup. Environ. Med. 1960, 17, 260-271. [CrossRef] [PubMed]

6. Doll, R. Mortality from lung cancer in asbestos workers 1955. Occup. Environ. Med. 1993, 50, 485-490. [CrossRef] [PubMed]

7. Kim, R.Y.; Sterman, D.H.; Haas, A.R. Malignant Mesothelioma: Has Anything Changed? Semin. Respir. Crit. Care Med. 2019, 40, 347-360. [CrossRef]

8. IARC Working Group on the Evaluation of Carcinogenic Risk to Humans. Arsenic, Metals, Fibres and Dusts. Lyon (FR): International Agency for Research on Cancer. (IARC Monographs on the Evaluation of Carcinogenic Risks to Humans, No. 100C.) ERIONITE. 2012. Available online: https://www.ncbi.nlm.nih. gov/books/NBK304368/ (accessed on 25 October 2019).

9. Metintas, M.; Hillerdal, G.; Metintas, S. Malignant mesothelioma due to environmental exposure to erionite: Follow-up of a Turkish emigrant cohort. Eur. Respir. J. 1999, 13, 523-526. [CrossRef]

10. National Research Council (US) Committee on Nonoccupational Health Risks of Asbestiform Fibers. 2, Asbestiform Fibers: Historical Background, Terminology, and Physicochemical Properties. In Asbestiform Fibers: Nonoccupational Health Risks; National Academies Press: Washington, DC, USA, 1984. Available online: https://www.ncbi.nlm.nih.gov/books/NBK216753/ (accessed on 25 October 2019). 
11. Korchevskiy, A.; Rasmuson, J.O.; Rasmuson, E.J. Rasmuson. Empirical model of mesothelioma potency factors for different mineral fibers based on their chemical composition and dimensionality. Inhal. Toxicol. 2019, 31, 180-191. [CrossRef]

12. Donaldson, K.; Murphy, F.A.; Duffin, R.; Poland, C. Asbestos, carbon nanotubes and the pleural mesothelium: A review of the hypothesis regarding the role of long fibre retention in the parietal pleura, inflammation and mesothelioma. Part Fibre Toxicol. 2010, 7. [CrossRef]

13. Yap, T.A.; Aerts, J.G.; Popat, S.; Fennell, D.A. Novel insights into mesothelioma biology and implications for therapy. Nat. Rev. Cancer 2017, 17, 475-488. [CrossRef] [PubMed]

14. Kehrer, J.P. The Haber-Weiss reaction and mechanisms of toxicity. Toxicology 2000, 149, 43-50. [CrossRef]

15. Pelclová, D.; Fenclová, Z.; Kacer, P.; Kuzma, M.; Navrátil, T.; Lebedová, J. Increased 8-isoprostane, a marker of oxidative stress in exhaled breath condensate in subjects with asbestos exposure. Ind. Heal. 2008, 46, 484-489. [CrossRef] [PubMed]

16. Bibby, A.C.; Tsim, S.; Kanellakis, N.; Ball, H.; Talbot, D.C.; Blyth, K.G.; Maskell, N.A.; Psallidas, I. Malignant pleural mesothelioma: an update on investigation, diagnosis and treatment. Eur. Respir. Rev. 2016, 25, 472-486. [CrossRef] [PubMed]

17. Ledda, C.; Senia, P.; Rapisarda, V. Biomarkers for Early Diagnosis and Prognosis of Malignant Pleural Mesothelioma: The Quest Goes on. Cancers 2018, 10, 203. [CrossRef]

18. Baas, P.; Fennell, D.; Kerr, K.M.; Van Schil, P.E.; Haas, R.L.; Peters, S. Malignant pleural mesothelioma: ESMO Clinical Practice Guidelines for diagnosis, treatment and follow-up. Ann. Oncol. 2015, 26, v31-v39. [CrossRef]

19. Porcel, J.M. Biomarkers in the diagnosis of pleural diseases: A 2018 update. Ther. Adv Respir. Dis. $2018,12$. [CrossRef]

20. Foddis, R.; Bonotti, A.; Landi, S.; Fallahi, P.; Guglielmi, G.; Cristaudo, A. Biomarkers in the prevention and follow-up of workers exposed to asbestos. J. Thorac. Dis. 2018, 10, S360-S368. [CrossRef]

21. Hooper, C.E.; Morley, A.J.; Virgo, P.; Harvey, J.E.; Kahan, B.; Maskell, N.A. A prospective trial evaluating the role of mesothelin in undiagnosed pleural effusions. Eur. Respir. J. 2013, 41, 18-24. [CrossRef]

22. Jakubec, P.; Pelclova, D.; Smolkova, P.; Kolek, V.; Nakladalova, M. Significance of serum mesothelin in an asbestos-exposed population in the Czech Republic. Biomed. Pap. 2015, 159, 472-479. [CrossRef]

23. Cristaudo, A.; Foddis, R.; Vivaldi, A.; Guglielmi, G.; DiPalma, N.; Filiberti, R.; Neri, M.; Ceppi, M.; Paganuzzi, M.; Ivaldi, G.P.; et al. Clinical Significance of Serum Mesothelin in Patients with Mesothelioma and Lung Cancer. Clin. Cancer Res. 2007, 13, 5076-5081. [CrossRef] [PubMed]

24. Cristaduo, A.; Foddis, R.; Bonotti, A.; Simonini, S.; Vivaldi, A.; Guglielmi, G.; Bruno, R.; Gemignani, F.; Landi, S. Two novel polymorphisms in 5'flanking region of the mesothelin gene are associated with soluble mesothelin-related peptide (SMRP) levels. Int. J. Biol. Markers 2011, 26, 117-123. [CrossRef] [PubMed]

25. Cristaudo, A.; Foddis, R.; Bonotti, A.; Simonini, S.; Vivaldi, A.; Guglielmi, G.; Bruno, R.; Landi, D.; Gemignani, F.; Landi, S. Polymorphisms in the putative micro-RNA-binding sites of mesothelin gene are associated with serum levels of mesothelin-related protein. Occup. Environ. Med. 2010, 67, 233-236. [CrossRef] [PubMed]

26. Felten, M.K.; Khatab, K.; Knoll, L.; Schettgen, T.; Müller-Berndorff, H.; Kraus, T. Changes of mesothelin and osteopontin levels over time in formerly asbestos-exposed power industry workers. Int. Arch. Occup. Environ. Health 2014, 87, 195-204. [CrossRef] [PubMed]

27. Hu, Z.-D.; Liu, X.-F.; Liu, X.-C.; Ding, C.-M.; Hu, C.-J. Diagnostic accuracy of osteopontin for malignant pleural mesothelioma: A systematic review and meta-analysis. Clin. Chim. Acta 2014, 433, 44-48. [CrossRef] [PubMed]

28. Greillier, L.; Baas, P.; Welch, J.J.; Hasan, B.; Passioukov, A. Biomarkers for Malignant Pleural Mesothelioma. Mol. Diagn. Ther. 2008, 12, 375-390. [CrossRef] [PubMed]

29. Cristaudo, A.; Bonotti, A.; Simonini, S.; Vivaldi, A.; Guglielmi, G.; Ambrosino, N.; Chella, A.; Lucchi, M.; Mussi, A.; Foddis, R. Combined Serum Mesothelin and Plasma Osteopontin Measurements in Malignant Pleural Mesothelioma. J. Thorac. Oncol. 2011, 6, 1587-1593. [CrossRef] [PubMed]

30. Johnen, G.; MoMar Study Group; Burek, K.; Raiko, I.; Wichert, K.; Pesch, B.; Weber, D.G.; Lehnert, M.; Casjens, S.; Hagemeyer, O.; et al. Prediagnostic detection of mesothelioma by circulating calretinin and mesothelin - a case-control comparison nested into a prospective cohort of asbestos-exposed workers. Sci. Rep. 2018, 8, 14321. [CrossRef] 
31. Jiménez-Ramírez, C.; Casjens, S.; Juárez-Pérez, C.A.; Raiko, I.; Del Razo, L.M.; Taeger, D.; Calderón-Aranda, E.S.; Rihs, H.-P.; Acosta-Saavedra, L.C.; Weber, D.G.; et al. Mesothelin, Calretinin, and Megakaryocyte Potentiating Factor as Biomarkers of Malignant Pleural Mesothelioma. Lung 2019, 197, 641-649. [CrossRef]

32. Davis, M.D.; Fowler, S.J.; Montpetit, A.J. Montpetit. Exhaled breath testing-A tool for the clinician and researcher. Paediatr. Respir. Rev. 2019, 29, 37-41. [CrossRef]

33. Davis, M.D.; Montpetit, A.; Hunt, J. Exhaled breath condensate: An overview. Immunol. Allergy Clin. N. Am. 2012, 32, 363-375. [CrossRef] [PubMed]

34. Haick, H.; Broza, Y.Y.; Mochalski, P.; Ruzsanyi, V.; Amann, A. Assessment, origin, and implementation of breath volatile cancer markers. Chem. Soc002E Rev. 2014, 43, 1423-1449. [CrossRef] [PubMed]

35. Amann, A.; Miekisch, W.; Schubert, J.; Buszewski, B.; Ligor, T.; Jezierski, T.; Pleil, J.; Risby, T. Analysis of Exhaled Breath for Disease Detection. Annu. Rev. Anal. Chem. 2014, 7, 455-482. [CrossRef] [PubMed]

36. Van Der Schee, M.P.; Paff, T.; Brinkman, P.; Van Aalderen, W.M.C.; Haarman, E.G.; Sterk, P.J. Breathomics in Lung Disease. Chest 2015, 147, 224-231. [CrossRef]

37. Lee, C.W.; Mohr, S.N.; Weisel, C.P. Toxicokinetics of human exposure to methyl tertiary-butyl ether (MTBE) following short-term controlled exposures. J. Expo. Sci. Environ. Epidemiol. 2001, 11, 67-68. [CrossRef]

38. Lavra, L.; Catini, A.; Ulivieri, A.; Capuano, R.; Salehi, L.B.; Sciacchitano, S.; Bartolazzi, A.; Nardis, S.; Paolesse, R.; Martinelli, E.; et al. Investigation of VOCs associated with different characteristics of breast cancer cells. Sci. Rep. 2015, 5, 13246. [CrossRef]

39. Dutta, D.; Chong, N.S.; Lim, S.H. Endogenous volatile organic compounds in acute myeloid leukemia: Origins and potential clinical applications. J. Breath Res. 2018, 12, 034002. [CrossRef]

40. Watanabe, M. Polymorphic CYP genes and disease predisposition-what have the studies shown so far? Toxicol. Lett. 1998, 102, 167-171. [CrossRef]

41. Antoniou, S.X.; Gaude, E.; Ruparel, M.; Van Der Schee, M.P.; Janes, S.M.; Rintoul, R.C.; on behalf of LuCID research group. The potential of breath analysis to improve outcome for patients with lung cancer. J. Breath Res. 2019, 13, 034002. [CrossRef]

42. Poli, D.; Carbognani, P.; Corradi, M.; Goldoni, M.; Acampa, O.; Balbi, B.; Bianchi, L.; Rusca, M.; Mutti, A. Exhaled volatile organic compounds in patients with non-small cell lung cancer: cross sectional and nested short-term follow-up study. Respir. Res. 2005, 6, 71. [CrossRef]

43. Filipiak, W.; Filipiak, A.; Sponring, A.; Schmid, T.; Zelger, B.; Ager, C.; Klodzinska, E.; Denz, H.; Pizzini, A.; Lucciarini, P.; et al. Comparative analyses of volatile organic compounds (VOCs) from patients, tumors and transformed cell lines for the validation of lung cancer-derived breath markers. J. Breath Res. 2014, 8, 27111. [CrossRef] [PubMed]

44. Marien, E.; Meister, M.; Muley, T.; Fieuws, S.; Bordel, S.; Derua, R.; Spraggins, J.; Van De Plas, R.; Dehairs, J.; Wouters, J.; et al. Non-small cell lung cancer is characterized by dramatic changes in phospholipid profiles. Int. J. Cancer 2015, 137, 1539-1548. [CrossRef] [PubMed]

45. Chow, S.; Campbell, C.; Sandrini, A.; Thomas, P.S.; Johnson, A.R.; Yates, D.H. Exhaled breath condensate biomarkers in asbestos-related lung disorders. Respir. Med. 2009, 103, 1091-1097. [CrossRef] [PubMed]

46. Sandrini, A.; Johnson, A.R.; Thomas, P.S.; Yates, D.H. Fractional exhaled nitric oxide concentration is increased in asbestosis and pleural plaques. Respirol. 2006, 11, 325-329. [CrossRef] [PubMed]

47. Lehtonen, H.; Oksa, P.; Lehtimäki, L.; Sepponen, A.; Nieminen, R.; Kankaanranta, H.; Saarelainen, S.; Järvenpää, R.; Uitti, J.; Moilanen, E. Increased alveolar nitric oxide concentration and high levels of leukotriene B4 and 8-isoprostane in exhaled breath condensate in patients with asbestosis. Thorax 2007, 62, 602-607. [CrossRef]

48. Ahmadzai, H.; Huang, S.; Hettiarachchi, R.; Lin, J.-L.; Thomas, P.S.; Zhang, Q. Exhaled breath condensate: A comprehensive update. Clin. Chem. Lab. Med. 2013, 51, 1343-1361. [CrossRef]

49. $\mathrm{Ng}$, A.W.; Bidani, A.; Thomas, A. Heming. Innate host defense of the lung: Effects of lung-lining fluid $\mathrm{pH}$. Lung 2004, 182, 297-317. [CrossRef]

50. Corradi, M.; Gergelova, P.; Mutti, A. Use of exhaled breath condensate to investigate occupational lung diseases. Curr. Opin. Allergy Clin. Immunol. 2010, 10, 93-98. [CrossRef]

51. Milne, G.L.; Yin, H.; Hardy, K.D.; Davies, S.S.; Roberts, L.J., 2nd. Isoprostane generation and function. Chem. Rev. 2011, 111, 5973-5996. [CrossRef] 
52. Pelclova, D.; Fenclová, Z.; Vlcková, S.; Lebedová, J.; Syslová, K.; Pecha, O.; Belácek, J.; Navrátil, T.; Kuzma, M.; Kacer, P. Leukotrienes B4, C4, D4 and E4 in the exhaled breath condensate (EBC), blood and urine in patients with pneumoconiosis. Ind. Health 2012, 50, 299-306.

53. Alonso, M.; Sanchez, J.M. Analytical challenges in breath analysis and its application to exposure monitoring. TrAC Trends Anal. Chem. 2013, 44, 78-89. [CrossRef]

54. Wallace, M.A.G.; Pleil, J.D. Evolution of clinical and environmental health applications of exhaled breath research: Review of methods and instrumentation for gas-phase, condensate, and aerosols. Anal. Chim. Acta 2018, 1024, 18-38. [CrossRef]

55. Horváth, I.; Barnes, P.J.; Loukides, S.; Sterk, P.J.; Högman, M.; Olin, A.-C.; Amann, A.; Antus, B.; Baraldi, E.; Bikov, A.; et al. A European Respiratory Society technical standard: exhaled biomarkers in lung disease. Eur. Respir. J. 2017, 49, 1600965. [CrossRef] [PubMed]

56. Rattray, N.J.; Hamrang, Z.; Trivedi, D.K.; Goodacre, R.; Fowler, S.J. Taking your breath away: metabolomics breathes life in to personalized medicine. Trends Biotechnol. 2014, 32, 538-548. [CrossRef] [PubMed]

57. Montuschi, P.; Santonico, M.; Mondino, C.; Pennazza, G.; Mantini, G.; Martinelli, E.; Capuano, R.; Ciabattoni, G.; Paolesse, R.; Di Natale, C.; et al. Diagnostic Performance of an Electronic Nose, Fractional Exhaled Nitric Oxide, and Lung Function Testing in Asthma. Chest 2010, 137, 790-796. [CrossRef] [PubMed]

58. Schubert, J.K.; Miekisch, W.; Geiger, K.; Nöldge-Schomburg, G.F. Breath analysis in critically ill patients: potential and limitations. Expert Rev. Mol. Diagn. 2004, 4, 619-629. [CrossRef]

59. Cavaleiro Rufo, J.; Paciência, I.; Mendes, F.C.; Farraia, M.; Rodolfo, A.; Silva, D.; de Oliveira Fernandes, E.; Delgado, L.; Moreira, A. Exhaled breath condensate volatilome allows sensitive diagnosis of persistent asthma. Allergy 2019, 74, 527-534. [CrossRef]

60. Baumbach, J.I. Ion mobility spectrometry coupled with multi-capillary columns for metabolic profiling of human breath. J. Breath Res. 2009, 3, 34001. [CrossRef]

61. Tran, V.H.; Chan, H.P.; Thurston, M.; Jackson, P.; Lewis, C.; Yates, D.; Bell, G.; Thomas, P.S. Breath Analysis of Lung Cancer Patients Using an Electronic Nose Detection System. IEEE Sensors J. 2010, 10, 1514-1518. [CrossRef]

62. Bikov, A.; Hernadi, M.; Korosi, B.Z.; Kunos, L.; Zsamboki, G.; Sutto, Z.; Tarnoki, A.D.; Tarnoki, D.L.; Losonczy, G.; Horváth, I. Expiratory flow rate, breath hold and anatomic dead space influence electronic nose ability to detect lung cancer. BMC Pulm. Med. 2014, 14, 202. [CrossRef]

63. Gasparri, R.; Santonico, M.; Valentini, C.; Sedda, G.; Borri, A.; Petrella, F.; Maisonneuve, P.; Pennazza, G.; D'Amico, A.; Di Natale, C.; et al. Volatile signature for the early diagnosis of lung cancer. J. Breath Res. 2016, 10, 16007. [CrossRef] [PubMed]

64. Dragonieri, S.; Annema, J.T.; Schot, R.; Van Der Schee, M.P.; Spanevello, A.; Carratu, P.; Resta, O.; Rabe, K.F.; Sterk, P.J. An electronic nose in the discrimination of patients with non-small cell lung cancer and COPD. Lung Cancer 2009, 64, 166-170. [CrossRef] [PubMed]

65. Moher, D.; Liberati, A.; Tetzlaff, J.; Altman, D.G. Preferred Reporting Items for Systematic Reviews and Meta-Analyses: The PRISMA Statement. Ann. Intern. Med. 2009, 151, 264-269. [CrossRef] [PubMed]

66. Review Manager (RevMan) [Computer Program]; Version 5.3; The Nordic Cochrane Centre; The Cochrane Collaboration: Copenhagen, Denmark, 2014.

67. Wells, G.; Shea, B.; O'Connell, D.; Peterson, J.; Welch, V.; Losos, M.; Tugwell, P. The Newcastle-Ottawa Scale (NOS) for Assessing the Quality of Nonrandomised Studies in Meta-Analysis. Available online: http://www.ohri.ca/programs/clinical_epidemiology/oxford.asp (accessed on 23 September 2019).

68. Thomson Reuters Endnote X9. Available online: https://endnote.com/product-details/ (accessed on 20 October 2019).

69. De Gennaro, G.; Dragonieri, S.; Longobardi, F.; Musti, M.; Stallone, G.; Trizio, L.; Tutino, M. Chemical characterization of exhaled breath to differentiate between patients with malignant plueral mesothelioma from subjects with similar professional asbestos exposure. Anal. Bioanal. Chem. 2010, 398, 3043-3050. [CrossRef]

70. Dragonieri, S.; Van Der Schee, M.P.; Massaro, T.; Schiavulli, N.; Brinkman, P.; Pinca, A.; Carratu, P.; Spanevello, A.; Resta, O.; Musti, M.; et al. An electronic nose distinguishes exhaled breath of patients with Malignant Pleural Mesothelioma from controls. Lung Cancer 2012, 75, 326-331. [CrossRef]

71. Chapman, E.A.; Thomas, P.S.; Stone, E.; Lewis, C.; Yates, D.H. A breath test for malignant mesothelioma using an electronic nose. Eur. Respir. J. 2012, 40, 448-454. [CrossRef] 
72. Lamote, K.; Vynck, M.; Van Cleemput, J.; Thas, O.; Nackaerts, K.; Van Meerbeeck, J.P. Detection of malignant pleural mesothelioma in exhaled breath by multicapillary column/ion mobility spectrometry (MCC/IMS). J. Breath Res. 2016, 10, 46001. [CrossRef]

73. Lamote, K.; Brinkman, P.; Vandermeersch, L.; Vynck, M.; Sterk, P.J.; Van Langenhove, H.; Thas, O.; Van Cleemput, J.; Nackaerts, K.; Van Meerbeeck, J.P. Breath analysis by gas chromatography-mass spectrometry and electronic nose to screen for pleural mesothelioma: a cross-sectional case-control study. Oncotarget 2017, 8, 91593-91602. [CrossRef]

74. Lamote, K.; Vynck, M.; Thas, O.; Van Cleemput, J.; Nackaerts, K.; Van Meerbeeck, J.P. Exhaled breath to screen for malignant pleural mesothelioma: a validation study. Eur. Respir. J. 2017, 50, 1700919. [CrossRef]

75. Scherpereel, A.; Astoul, P.; Baas, P.; Berghmans, T.; Clayson, H.; de Vuyst, P.; Dienemann, H.; Galateau-Salle, F.; Hennequin, C.; Hillerdal, G.; et al. Guidelines of the European Respiratory Society and the European Society of Thoracic Surgeons for the management of malignant pleural mesothelioma. Eur. Respir. J. 2010, 35, 479-495. [CrossRef]

76. Landi, M.T.; Consonni, D.; Rotunno, M.; Bergen, A.W.; Goldstein, A.M.; Lubin, J.H.; Goldin, L.; Alavanja, M.; Morgan, G.; Subar, A.F.; et al. Environment and Genetics in Lung cancer Etiology (EAGLE) study: An integrative population-based case-control study of lung cancer. BMC Public Heal. 2008, 8, 203. [CrossRef] [PubMed]

77. Gross, P.; Zapp, J.A. Biologic activity of $\varepsilon$-caprolactam. CRC Crit. Rev. Toxicol. 1984, 13, 205-216. [CrossRef] [PubMed]

78. Altomare, D.F.; Di Lena, M.; Porcelli, F.; Trizio, L.; Travaglio, E.; Tutino, M.; Dragonieri, S.; Memeo, V.; de Gennaro, G. Exhaled volatile organic compounds identify patients with colorectal cancer. Br. J. Surg. 2013, 100, 144-150. [CrossRef] [PubMed]

79. Oguma, T.; Nagaoka, T.; Kurahashi, M.; Kobayashi, N.; Yamamori, S.; Tsuji, C.; Takiguchi, H.; Niimi, K.; Tomomatsu, H.; Tomomatsu, K.; et al. Clinical contributions of exhaled volatile organic compounds in the diagnosis of lung cancer. PLoS ONE 2017, 12, e0174802. [CrossRef] [PubMed]

80. agniau, S.; Lamote, K.; Van Meerbeeck, J.P.; Vermaelen, K.Y. Biomarkers for early diagnosis of malignant mesothelioma: Do we need another moonshot? Oncotarget 2017, 8, 53751-53762.

81. Dragonieri, S.; Quaranta, V.N.; Carratu, P.; Ranieri, T.; Resta, O. Influence of age and gender on the profile of exhaled volatile organic compounds analyzed by an electronic nose. J. Bras. de Pneumol. 2016, 42, 143-145. [CrossRef]

82. Blanchet, L.; Smolinska, A.; Baranska, A.; Tigchelaar, E.; Swertz, M.; Zhernakova, A.; Dallinga, J.W.; Wijmenga, C.; Van Schooten, F.J. Factors that influence the volatile organic compound content in human breath. J. Breath Res. 2017, 11, 016013. [CrossRef]

83. Capone, S.; Tufariello, M.; Forleo, A.; Longo, V.; Giampetruzzi, L.; Radogna, A.V.; Casino, F.; Siciliano, P. Chromatographic analysis of VOC patterns in exhaled breath from smokers and nonsmokers. Biomed. Chromatogr. 2018, 32. [CrossRef]

84. LeBouf, R.F.; Virji, M.A.; Saito, R.; Henneberger, P.K.; Simcox, N.; Stefaniak, A.B. Exposure to volatile organic compounds in healthcare settings. Occup. Environ. Med. 2014, 71, 642-650. [CrossRef]

85. Bessoneau, V.; Mosqueron, L.; Berrubé, A.; Mukensturm, G.; Buffet-Bataillon, S.; Gangneux, J.-P.; Thomas, O. VOC contamination in hospital from stationary sampling of a large panel of compounds, in view of healthcare workers and patients exposure assessment. PLoS ONE 2013, 8, e55535. [CrossRef]

(C) 2020 by the authors. Licensee MDPI, Basel, Switzerland. This article is an open access article distributed under the terms and conditions of the Creative Commons Attribution (CC BY) license (http://creativecommons.org/licenses/by/4.0/). 